\title{
Association of allergic rhinitis or asthma with pollen and chemical pollutants in Szeged, Hungary, 1999-2007
}

\author{
László Makra • István Matyasovszky • Beatrix Bálint • \\ Zoltán Csépe
}

Received: 6 September 2012 /Revised: 26 February 2013 / Accepted: 26 February 2013 /Published online: 5 April 2013

(C) ISB 2013

\begin{abstract}
The effect of biological (pollen) and chemical air pollutants on respiratory hospital admissions for the Szeged region in Southern Hungary is analysed. A 9-year (19992007) database includes - besides daily number of respiratory hospital admissions-daily mean concentrations of $\mathrm{CO}$, $\mathrm{PM}_{10}, \mathrm{NO}, \mathrm{NO}_{2}, \mathrm{O}_{3}$ and $\mathrm{SO}_{2}$. Two pollen variables (Ambrosia and total pollen excluding Ambrosia) are also included. The analysis was performed for patients with chronic respiratory complaints (allergic rhinitis or asthma bronchiale) for two age categories (adults and the elderly) of males and females. Factor analysis was performed to clarify the relative importance of the pollutant variables affecting respiratory complaints. Using selected low and high quantiles corresponding to probability distributions of respiratory hospital admissions, averages of two data sets of each air pollutant variable were evaluated. Elements of these data sets were chosen according to whether actual daily patient numbers were below or above their quantile value. A nonparametric regression technique was applied to discriminate between extreme and nonextreme numbers of respiratory admissions using pollen and
\end{abstract}

\section{Makra $(\bowtie) \cdot$ Z. Csépe}

Department of Climatology and Landscape Ecology, University of Szeged, POB 653, 6701 Szeged, Hungary

e-mail:makra@geo.u-szeged.hu

Z. Csépe

e-mail: csepe.zoltan@gmail.com

\section{Matyasovszky}

Department of Meteorology, Eötvös Loránd University, Pázmány

Péter st. 1/A,

1117 Budapest, Hungary

e-mail: matya@ludens.elte.hu

\section{B. Bálint}

Hospital of Chest Diseases, Alkotmány u. 36,

Csongrád County, 6772 Deszk, Hungary

e-mail: balint@deszkikorhaz.hu chemical pollutants as explanatory variables. The strongest correlations between extreme patient numbers and pollutants can be observed during the pollen season of Ambrosia, while the pollen-free period exhibits the weakest relationships. The elderly group with asthma bronchiale is characterised by lower correlations between extreme patient numbers and pollutants compared to adults and allergic rhinitis, respectively. The ratio of the number of correct decisions on the exceedance of a quantile resulted in similar conclusions as those obtained by using multiple correlations.

Keywords Air pollution · Allergenic pollen · Respiratory hospital admissions $\cdot$ Patient number $\cdot$ Allergic rhinitis . Asthma bronchiale

\section{Introduction}

Air pollution - a major and constantly rising hazard in the environment associated with large increases in medical expenses and morbidity - is estimated to cause about 800,000 premature deaths annually worldwide (Cohen et al. 2005). Considering respiratory diseases, asthma is a global health problem affecting around 300 million patients in all countries around the world (Kupczyk and Wenzel 2012). Clinical evidence reveals a substantial increase in both incidence and prevalence of respiratory diseases such as allergic rhinitis and asthma (Albertini et al. 2012; Ziello et al. 2012). This increase may be related not only to climate change, chemical air pollution and changes in lifestyle (Kiss and Béres 2006; Cecchi et al. 2010), but also to an increase in the actual airborne concentrations of allergenic pollen (Ziello et al. 2012). Global warming is recognised increasingly as a major risk to human health. The continuing increase in atmospheric $\mathrm{CO}_{2}$ levels, as a major component of climate change 
associated with urbanisation (Ziska et al. 2007), can influence public health directly by stimulating the growth and pollen production of allergy-inducing species such as ragweed (Ziska and Caulfield 2000; Rogers et al. 2006; Ziska et al. 2007).

Allergic rhinitis (AR) is a common inflammatory condition of the nasal mucosa characterised by nasal pruritus, sneezing, rhinorrhoea, and nasal congestion. AR is mediated by an IgEassociated response to ubiquitous indoor and/or outdoor environmental allergens (Dullaers et al. 2012).

Asthma is defined as a chronic inflammatory disorder, where chronic inflammation is associated with airway hyperresponsiveness that leads to recurrent episodes of wheezing, breathlessness, chest tightness and coughing, particularly at night or in the early morning (Global Strategy for Asthma Management and Prevention 2010). Asthma is caused by environmental and genetic factors (Martinez 2007), which influence the severity of asthma. The interaction of these factors is complex and not fully understood (Miller and Ho 2008).

Many patients with asthma, particularly those with allergic asthma, also have AR. The mucosa of the upper and lower airways is continuous, and the type of inflammation in AR and asthma is very similar, involving $\mathrm{T}$ helper type 2 cells, mast cells, and eosinophils (Jeffery and Haahtela 2006). Both diseases have characteristic symptoms and are influenced strongly by environmental factors.

A number of characteristics that can lead to an increased risk of pollutant-related respiratory diseases have been identified, including sex, age (i.e. children, adults and the elderly), pre-existing respiratory disease and low socio-economic status (Sacks et al. 2011).

The harmful effects of ozone $\left(\mathrm{O}_{3}\right)$, nitrogen dioxide $\left(\mathrm{NO}_{2}\right)$ and particulate matter (PM) on respiratory symptoms and functions are well documented (Chung et al. 2011; Nuvolone et al. 2011; Zhang et al. 2011). Recent studies, particularly in urban areas, have suggested a role of pollutants in the development of respiratory diseases (Chiusolo et al. 2011; Darrow et al. 2011; Namdeo et al. 2011). Evidence is emerging that traffic-related pollutants may contribute to the development of allergy (Kelly and Fussell 2011; Koppen et al. 2011). Furthermore, numerous epidemiological and experimental studies suggest an association between exposure to ambient $\mathrm{NO}_{2}, \mathrm{O}_{3}$ and $\mathrm{PM}$ and an increased susceptibility to respiratory morbidity (Giovannini et al. 2010; Kim et al. 2011; Tramuto et al. 2011).

The substantial increase in respiratory diseases in industrialised countries is attributable partly to a combination of chemical air pollutants and allergenic pollen existing in the air of big cities (Gowers et al. 2012). Several papers have analysed separately the effects of either chemical air pollutants (Chiu et al. 2009; Alves et al. 2010) or allergenic pollen (Díaz et al. 2007; Hanigan and Johnston 2007; Carracedo-Martínez et al. 2008) on the frequency of hospital admissions for respiratory diseases; however, only very few studies have yet examined the effect of both these variables together (e.g. Andersen et al. 2007; Magas et al. 2007). Such studies revealed a significant effect between partly the pollen and chemical compounds and partly health for admitted respiratory patients, and this effect was higher than that detected separately for either the chemical air pollutants or pollen.

Air pollution in Hungary is one of the highest in Europe. An estimated 16,000 annual premature deaths in the country are attributable to exposure to ambient $\mathrm{PM}_{10}$ concentrations (Barrett et al. 2008; Ågren 2010). Furthermore, airborne pollen levels are also high. The Carpathian basin involving Hungary (Fig. 1) is characterized by the highest airborne ragweed ( $\mathrm{Am}$ brosia) pollen concentrations in Europe. The ratio of captured Ambrosia pollen in Hungary in relation to the captured total pollen in the late summer period is around 60-71\% (Makra et al. 2005). The sensitivity of patients to ragweed in Szeged is $83.7 \%$ (Makra et al. 2005). About $30 \%$ of the Hungarian population has some type of allergy, $65 \%$ of them have pollensensitivity, and at least $60 \%$ of this pollen-sensitivity is caused by Ambrosia (Járai-Komlódi 1998). The number of patients with registered allergic illnesses has doubled and the number of cases of allergic asthma in Southern Hungary has quadrupled over the last 40 years (Járai-Komlódi 1998).

The purpose of this study was to analyse the effect of biological (pollen) and chemical air pollutants on daily respiratory hospital and outpatient admissions with AR and asthma bronchiale $(\mathrm{AB})$ for both adult and elderly patients of both genders over three different seasons in the Szeged region of Southern Hungary.

\section{Materials and methods}

\section{Study area}

Szeged $\left(46.25^{\circ} \mathrm{N} ; 20.10^{\circ} \mathrm{E}\right)$ is the largest settlement in Southeastern Hungary (Fig. 1). The area is characterised by the extensive flat landscape of the Great Hungarian Plain with an elevation of $79 \mathrm{~m}$ above mean sea level. The built-up area covers a region of about $46 \mathrm{~km}^{2}$. The city is the centre of the Szeged region and has 203,000 inhabitants.

\section{Pollen data}

The pollen content of the air was measured using a 7-day recording "Hirst-type" volumetric trap (Hirst 1952). The air sampler is located about $20 \mathrm{~m}$ above the ground (Fig. 1, lower panel). After sampling, in order to determine pollen type and counts, a light microscope was applied at a magnification of $x$ 400. Five horizontal sweeps were analysed on each slide. The accuracy of the measurement was proportional to the number of sweeps and the concentration of particles. Counting was 
Fig. 1 Upper panel Location of Hungary within Europe. Lower panel Urban web of Szeged with the positions of the data sources: 1 monitoring station, 2 aerobiological station, 3 Hospital of Chest Diseases in Deszk

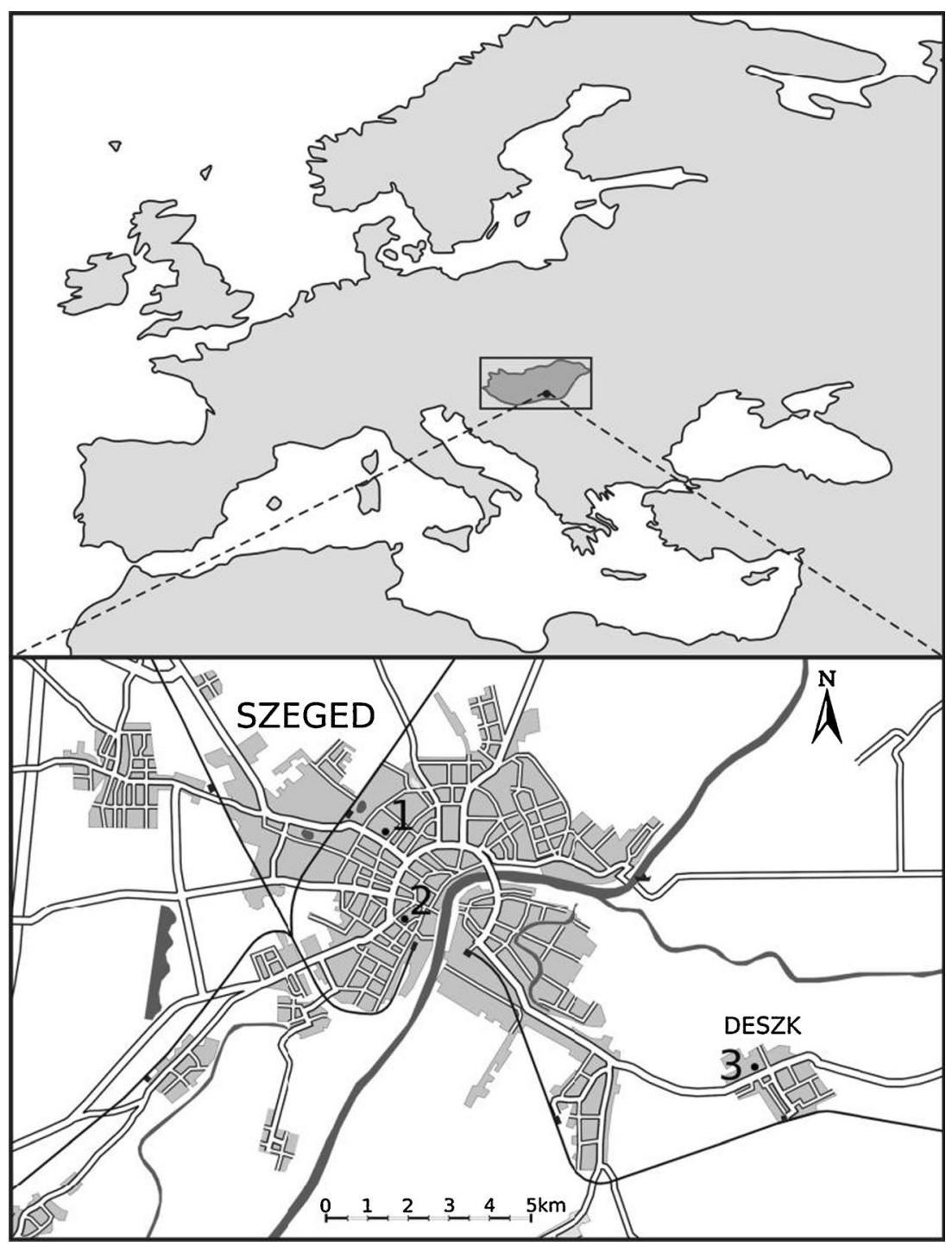

performed using a standard sampling procedure (Käpylä and Penttinen 1981; Peternel et al. 2006). Two pollen variables were formed for our analysis: special emphasis was places on the daily pollen counts of Ambrosia, due to its extremely high concentrations during its short pollen season, and the daily total pollen count (the pollen counts of each of the 24 taxa examined) excluding the pollen of Ambrosia. Pollen data were expressed as daily mean pollen concentration (pollen grains $/ \mathrm{m}^{3}$ ).

The analysis was performed for a 9-year (1999-2007) dataset. Three periods were considered: the first is the Ambrosia pollen season (15 July-16 October ); the second period lasts from 14 January (the start date of the pollination of Corylus) to 14 July and corresponds to the period when most pollen is captured; the third is the pollen-free period (17 October-13 January) in which the amount of airborne pollen is very low or zero. Ambrosia pollen and total pollen excluding Ambrosia pollen were the pollen variables applied during the first period (15 July-16 October), total pollen excluding
Ambrosia pollen was considered during the second period and any pollen variable was taken into account in the third period.

The pollen season is defined by its start and end dates. For the start (end) of the Ambrosia pollen season we used the 1st (last) day of the first (last) 6-day period, each day of which shows 1 or more pollen grains $\mathrm{m}^{-3}$ air (Galán et al. 2001). Evidently, the pollen season varies from year to year. The atmospheric pollen season was defined for each year and the longest observed over the 9-year period was taken into account to determine the three given periods. This definition was considered even if the remaining years involved substantially different pollen seasons with either markedly later start or notably earlier end of pollen release.

Chemical air pollutant data

Chemical air pollutants were collected in a monitoring station located in downtown Szeged at a distance of about $10 \mathrm{~m}$ from 
the busiest main road (Fig. 1). They included the daily average mass concentrations of $\mathrm{CO}\left(\mathrm{mg} \mathrm{m}^{-3}\right), \mathrm{NO}, \mathrm{NO}_{2}, \mathrm{SO}_{2}, \mathrm{O}_{3}$ and $\mathrm{PM}_{10}\left(\mu \mathrm{g} \mathrm{m}^{-3}\right.$ ) (Alves et al. 2010). Mean daily concentrations of the chemical air pollutants for the three periods are presented in Table 1.

\section{Patient data}

The daily number of hospital admissions registered with respiratory diseases came from the Hospital of Chest Diseases, Deszk, Csongrád County, located about $10 \mathrm{~km}$ from the monitoring station in downtown Szeged (Fig. 1, lower panel). The patients were admitted to the outpatient clinic and the hospital accepts patients directly from the ER without delay. Most of the patients were treated as out-patients. The diagnosis of allergy was defined according to the presence of appropriate clinical symptoms and signs associated with the evidence of IgE antibodies directed towards relevant allergens determined by a skin-prick test. If the result of the skin-prick test was not suitable for identifying the allergen, total IgE and specific IgE were measured from blood. Data on the age, sex, date of admission and disease type were all available for each patient.

Respiratory diseases were categorised using the International Classification of Diseases, Tenth Revision (ICD-10) (WHO 1999). All patients registered with the diagnosis of AR and asthma bronchiale - either as inpatients or outpatients during the study period - were included. More precisely, AR due to pollen (J3010), seasonal allergic rhinitis (J3020), other allergic rhinitis (J3030), non-specific allergic rhinitis (J3040), as well as allergic asthma (J4500), non-allergic asthma (J4510) and mixed asthma (J4580) were considered.

Two age groups were considered in the research: adult patients (15-64 years) and the elderly patients ( $\geq 65$ years). The younger age group ( $0-14$ years), was not analysed due to the very small patient numbers. Hence male and female patients for the adult and elderly age groups were considered. The population consisted of 133,464 hospital admissions of subjects resident in Szeged. The number of hospital admissions registered with respiratory diseases is summarised for different groups of patients and periods (Table 2). Note, that, as days without admission to the outpatient department, Saturdays, Sundays and holidays were excluded from the analysis.

The data set applied is unique in the sense that it includes both categories of air pollutants as influencing variables.
The study analyzes one of the largest data sets used in the literature on respiratory hospital admissions.

\section{Statistical analysis}

First, a factor analysis with special transformation was performed on the air pollutant and respiratory admission data in order to determine the strength and direction of the association of air pollutant and respiratory admission variables. Then, using selected low and high quantiles corresponding to probability distributions of AR and asthma, daily mean concentrations of pollen and chemical air pollutants were compared and evaluated. From here on, we refer to extreme patient number whenever the daily patient number is larger than the chosen high quantile of patients. Finally, two techniques were applied to discriminate between extreme and non-extreme respiratory admission variables using pollen and chemical air pollutants.

\section{Optimal time lags}

It is reasonable to allow time lags between pollutants concentrations and number of hospital admissions. A wide range of candidate time lags is applied in the literature to find the optimal time delay (e.g. Orazzo et al. 2009). Although there are examples of time lags of up to 5 days (Ko et al. 2007) and even 8 days (Nascimento et al. 2006), the literature generally shows delays of up to 3 days in patient response to pollution exposure (WHO 1992; Alves et al. 2010). It is likely that the explanatory variables express their effects until the formation of the respiratory problems within 3 days (Knight et al. 1991). Our optimal time lags were selected with the help of the $t$ values of regression coefficients. Namely, a time lag accompanied with the highest absolute $t$-value was chosen as optimal for each explanatory variable separately.

\section{Factor analysis and special transformation}

Factor analysis identifies any linear relationships among subsets of examined variables and this helps to reduce the dimensionality of the initial database without substantial loss of information. First, a factor analysis was applied to the initial dataset consisting of nine variables (eight explanatory variables and one resultant variable defined by the number of daily hospital and outpatient admissions with AR and asthma)

Table 1 Mean daily concentrations of the chemical air pollutants for the three periods examined

\begin{tabular}{lcccccc}
\hline Period: & $\mathrm{CO}\left(\mathrm{mg} \mathrm{m}^{-3}\right)$ & $\mathrm{PM}_{10}\left(\mu \mathrm{g} \mathrm{m}^{-3}\right)$ & $\mathrm{NO}\left(\mu \mathrm{g} \mathrm{m}^{-3}\right)$ & $\mathrm{NO}_{2}\left(\mu \mathrm{g} \mathrm{m}^{-3}\right)$ & $\mathrm{O}_{3}\left(\mu \mathrm{g} \mathrm{m}^{-3}\right)$ & $\mathrm{SO}_{2}\left(\mu \mathrm{g} \mathrm{m}^{-3}\right)$ \\
\hline 14 January-14 July & 464.2 & 39.6 & 13.3 & 28.4 & 39.7 & 6.2 \\
15 July-16 October & 425.4 & 36.7 & 13.1 & 26.6 & 37.3 & 4.7 \\
17 October-13 January & 627.8 & 48.3 & 25.6 & 27.2 & 15.0 & 7.9 \\
\hline
\end{tabular}


Table 2 Number of hospital admissions registered with respiratory diseases for different groups of patients and periods. $A R$ Allergic rhinitis; $A B$ asthma bronchiale

\begin{tabular}{|c|c|c|c|c|c|c|c|c|c|c|c|}
\hline \multirow[t]{3}{*}{ Period: } & \multicolumn{5}{|c|}{ Adults (15-64 years) } & \multicolumn{5}{|c|}{ Elderly ( $\geq 65$ years) } & \multirow[t]{3}{*}{ Total } \\
\hline & \multicolumn{2}{|l|}{ Male } & \multicolumn{2}{|c|}{ Female } & \multirow[t]{2}{*}{ Subtotal } & \multicolumn{2}{|l|}{ Male } & \multicolumn{2}{|c|}{ Female } & \multirow[t]{2}{*}{ Subtotal } & \\
\hline & $\mathrm{AR}$ & $\mathrm{AB}$ & $\mathrm{AR}$ & $\mathrm{AB}$ & & $\mathrm{AR}$ & $\mathrm{AB}$ & $\mathrm{AR}$ & $\mathrm{AB}$ & & \\
\hline 15 July-16 October & 1,996 & 5,846 & 1,711 & 10,124 & 19,677 & 428 & 4,420 & 713 & 5,133 & 10,694 & 30,371 \\
\hline 17 October-13 January & 2,994 & 8,270 & 1,141 & 10,837 & 23,242 & 1,283 & 6,417 & 1,711 & 5,704 & 15,115 & 38,357 \\
\hline 14 January-14 July & 2,424 & 13,974 & 4,278 & 18,964 & 39,640 & 2,281 & 12,263 & 1,426 & 9,126 & 25,096 & 64,736 \\
\hline Total & 7,414 & 28,090 & 7,130 & 39,925 & 82,559 & 3,992 & 23,100 & 3,850 & 19,963 & 50,905 & 133,464 \\
\hline
\end{tabular}

in order to transform the original variables to fewer variables. These new variables (called factors) can be viewed as latent variables that explain the behaviour of pollutant-hospital admission variables. The optimum number of retained factors can be determined by applying different statistical criteria (Jolliffe 1993). The most common and widely accepted criterion is to specify a least percentage ( $80 \%$ ) of the total variance in the original variables that has to be achieved (Liu 2009).

After performing the factor analysis, a special transformation of the retained factors was made in order to discover to what degree the above-mentioned explanatory variables affect the resultant variable, and to rank their influence (Fischer and Roppert 1965; Jahn and Vahle 1968). When performing a factor analysis on the standardised variables, the factor loadings obtained are correlation coefficients between the original variables and, after rotation, the coordinate values belonging to the rotated axes (namely, factor values). Consequently, if the resultant variable is correlated strongly with the factor; that is to say, if the factor has a high factor loading at the place of the resultant variable, and within the same factor an influencing variable is highly correlated with the factor, then the influencing variable is also highly correlated with the resultant variable. Accordingly, it is advisable to combine all the weights of the factors, together with the resultant variable, into one factor. Namely, it is effective to rotate such that only one factor has a big load with the resultant variable. The remaining factors are uncorrelated with the resultant variable; that is to say, they have zero weight (Fischer and Roppert 1965; Jahn and Vahle 1968). This latter procedure is called a special transformation.

t-test

Quantiles corresponding to probabilities $0.9,0.8$ and 0.7 were determined first. Note that a $P$-quantile $(0<P<1) q_{\mathrm{p}}$ is the value below which the daily number of patients occurs with relative frequency $P$. The above-mentioned chronic respiratory diseases were then assigned to two categories according to whether the actual daily number of admissions due to respiratory diseases was below the actual quantile or not. Values of daily chemical air pollutant and pollen variables corresponding to the number of respiratory hospital admissions below and above the quantiles $0.9,0.8,0.7$ were analysed. Specifically, the $t$-test (Zimmerman 1997) was used to decide whether the means of each chemical air pollutant and pollen variable differ significantly under each above mentioned quantiles.

\section{Nonparametric regression}

Let $Y$ be an indicator variable that takes the values 1 or 0 according to whether the daily patient number exceeds or does not exceed a quantile of patients. Our goal was to estimate the quantile exceedance probability conditioned on the explaining variables $X=\left(X_{1}, \ldots, X_{\mathrm{m}}\right)$. In order to avoid misspecification of the analytical form of the relationship between $X$ and $Y$ a nonparametric regression technique was applied. Because every variable has an annual cycle, the estimator uses data from only a time interval (time window) of the actual time $t$. Having a data set $\left(\mathbf{x}_{1}, y_{1}\right), \ldots,\left(\mathbf{x}_{\mathbf{n}}, y_{n}\right)$ available at instances $t_{1}, \ldots, t_{n}$ we extend the classical Nadaraya-Watson estimator to the time-varying case as

$\widehat{y}(\mathbf{x}, \mathbf{t})=\sum_{i=1}^{n} y_{i} K\left(\left\|\mathbf{x}_{\mathbf{i}}-\mathbf{x}\right\| / h\right) K\left(\left(t_{i}-t\right) / b\right) / \sum_{i=1}^{n} K\left(\left\|\mathbf{x}_{i}-\mathbf{x}\right\| / h\right) K\left(\left(t_{i}-t\right) / b\right)$

where $K(u)$ is a kernel function evaluated at $u$, and $b$ is the time window. Thus, the estimated probability is a weighted sum of the indicator values $y_{\mathrm{i}}$ accompanied with explanatory variables $x_{\mathrm{i}}$. The weights are controlled by the distance $\left\|\mathbf{x}_{\mathbf{i}}-\mathbf{x}\right\|$ via the kernel $K$, which is chosen here as the Epanechnikov kernel. Specifically, when $x_{\mathrm{i}}$ is close to $x$ the weight of $y_{\mathrm{i}}$ is large, while an $x_{\mathrm{i}}$ far from $x$ provides a small weight for $y_{\mathrm{i}}$. The so-called bandwidth $h$ plays a similar role to that of $b$; it controls the neighbourhood of the explaining variable $x$ where $x_{\mathrm{i}}$, and thus $y_{\mathrm{i}}$, are taken into account. The distance mentioned above is the Euclidean distance with a slight modification. Namely, in order to ensure the same potential importance of every explanatory 
variable, the variables are divided first by their standard deviations. Hence, $h$ has no unit.

A rigorous mathematical background of nonparametric regression techniques including ideas to choose the kernel and estimate $h$ and $b$ can be found, e.g. in Fan and Yao (2005).

The goodness-of-fit of estimating quantile exceedance probabilities conditioned on the explanatory variables is measured by $R=(1-M S E / V)^{1 / 2}$, where $M S E=1 / n \sum_{i=1}^{n}$ $\left(\widehat{y}\left(\mathbf{x}_{\mathbf{i}}, t_{i}\right)-y\left(\mathbf{x}_{\mathbf{i}}, t_{i}\right)\right)^{2}$ and $V$ is the variance calculated from the indicator data $\left(y_{1}, \ldots, y_{n}\right)$. Because $R$ is identical with the multiple correlation for multivariate linear regressions, hereafter the quantity $R$ will be called multiple correlation.

Usually, a data set available is divided into a learning set and a validation set. The learning set is used to estimate parameters of the statistical model, and this model is then applied to the validation set. A general rule of thumb is to consider the learning set to be around $80 \%$ of the total data and the validation set to be the remaining $20 \%$. In this case, however, such a choice of validation set would cover only a small number of cases. Note that the parameters to be estimated in the nonparametric technique include the time window and bandwidth. Therefore, the validation should include only the proper selection of these parameters. Having Lyears of data, our validation makes it possible to use an $L$-year validation set with an $(L-1)$-year learning set. Taking the $k$ th year from the entire data set, the parameters are estimated with data omitting the $k$ th year, and estimates for the $k$ th year are then obtained using these parameters. The procedure is applied for $k=1, \ldots L$, and thus these estimates for the entire data set are validated directly. A simplification working with the mean of annually varying parameters can be made because the variability of the $L$ number time windows and bandwidths is very small. The section below describing "Conditional probabilities and events of exceeding quantities" will show these validated results.

\section{Test for statistically significant correlation}

Significance levels for multiple correlations between the explaining variables and the indicator variables defined by events of exceeding/not exceeding quantile values (see below) were determined by a Monte-Carlo simulation experiment. First, patient number data were reordered randomly. The original observed values were then replaced by these reordered data and the nonparametric regression technique performed. Finally, the multiple correlation obtained from this procedure was calculated. These steps were repeated 1,000 times, and the appropriate quantiles of the empirical probability distribution function of these 1,000 simulated correlations yielded the critical value for checking the nullhypothesis of being the multiple correlation zero.

\section{Results}

Although the total pollen excluding the pollen season of $\mathrm{Am}$ brosia comprises several allergens, this separation permits the respiratory health effects of the two pollen variables to be studied separately as Ambrosia dominates the pollen counts during the main part of its pollen season (Fig. 2).

Optimal time lags

The optimal time lags vary from 0 to 5 days. There is a tendency with increasing age for more non-zero lags. $\mathrm{NO}_{2}$
Fig. 2 Mean daily total pollen counts excluding Ambrosia pollen (14 January-14 July) and the mean daily pollen counts of Ambrosia (15 July-16

October), Szeged, 1999-2007

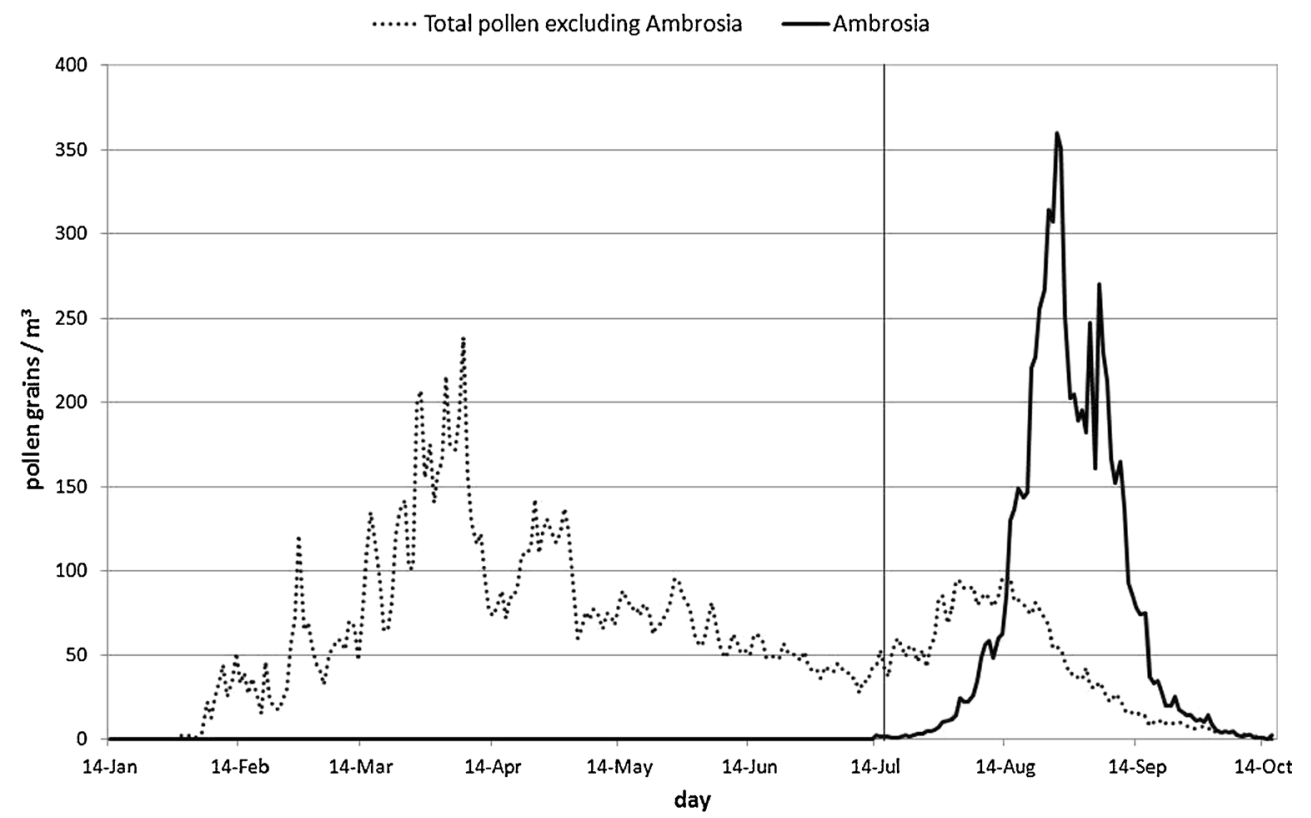


has the highest number of positive time shifts of all the air pollutants (typically 5 days for the pollen-free season and 5 days for the elderly in the pollination season excluding the pollen season of Ambrosia, while it is generally 2 days for the remaining period and categories) followed by $\mathrm{O}_{3}$ and NO. Among the chemical air pollutants, $0-3$ days and $0-4$ positive lags are associated with $\mathrm{SO}_{2}$ and $\mathrm{CO}$, respectively. At the same time, for $\mathrm{PM}_{10}$ uniform 2-day time lags are typical. As regards the age groups, the time delay is longest for the elderly, and shortest for adults. For the two pollen variables, the optimal time lags are the same for both age groups, namely 2 and 5 days for Ambrosia pollen and the remaining pollen, respectively.

Factor analysis with special transformation and $t$-test

After performing a factor analysis for adults and the elderly (for both categories male and female patients were considered, diagnosed with AR and asthma) for the three seasons (altogether $2 \times 2 \times 2 \times 3=24$ factor analyses), five factors were retained for each category in the pollen season of Ambrosia and in the pollen season of the total pollen excluding that of Ambrosia, respectively. At the same time, four factors were retained for each category in the pollen-free season. In order to calculate the rank of importance of the explanatory variables for determining the resultant variable, loadings of the retained factors were projected onto Factor 1 for all 24 factor analyses with the special transformation (Tables 3, 4, 5).

For the period 15 July-16 October, both diseases indicate substantially stronger pollutant-related associations for adults than for the elderly. For both age categories, AR shows stronger associations with the influencing variables than asthma. Furthermore, both adult male and adult female patients are practically equally endangered by chemical air pollutant-related asthma (Table 3). For adult male and adult female subjects, both pollen variables are of key importance in influencing the prevalence of AR. Ambrosia pollen is the most important factor for both male and female asthmatic patients; however, the total pollen excluding Ambrosia pollen has only a moderate-to-weak role. For the elderly, ozone $\left(\mathrm{O}_{3}\right)$ is the most important variable in influencing respiratory hospital admissions with the exception of asthma among males $\left(\mathrm{SO}_{2}\right)$, while the role of pollen variables decreased substantially (Table 3 ). The total weight of the chemical and pollen variables was about the same for adult males and adult females with AR, while chemical pollutants represented a higher total weight for asthma. Regarding elderly male and female patients with AR and asthma, chemical pollutants had a significantly higher total weight compared to that of the pollen variables (Table 3). For all adults, the pollen variables were the most important factor influencing the number of respiratory hospital admissions, while for all the elderly, $\mathrm{O}_{3}$ had the highest weight, with the total pollen excluding Ambrosia pollen as well as Ambrosia pollen were ranked 2 and 6 , respectively. Both pollen variables were statistically significant for the two categories. As regards the chemical variables for all adults and all the elderly, $\mathrm{O}_{3}$, $\mathrm{SO}_{2}$, and $\mathrm{PM}_{10}$ were the most relevant variables, while $\mathrm{NO}_{2}$ for adults and $\mathrm{NO}$ for the elderly were the least important pollutants (Table 3).

For the period 17 October -13 January, the chemical air pollutants displayed stronger associations with AR and asthma in adults than in the elderly. Medical visits due to AR indicate a substantially stronger association with the chemical variables than visits due to asthma in each category (Table 4). For adult male and female AR subjects, $\mathrm{NO}_{2}$ is the most important factor affecting respiratory admissions, while for adult females with asthma, $\mathrm{O}_{3}$ is the primary factor. Regarding elderly patients, $\mathrm{NO}_{2}, \mathrm{O}_{3}$ and $\mathrm{CO}$ are the key factors for males with $\mathrm{AR}$, while $\mathrm{NO}_{2}$ and $\mathrm{O}_{3}$ are key for females with $\mathrm{AR}$, and $\mathrm{O}_{3}$ for females with asthma. Besides this, based on the total weights, AR indicates the highest risk both for adult and elderly female patients (Table 4). The total weight of the explanatory variables is substantially higher for all elderly than for all adult patients. For all adults, only NO is a relevant influencing variable. While for all the elderly patients, $\mathrm{NO}_{2}, \mathrm{O}_{3}$ and $\mathrm{NO}$ (in decreasing order) are correlated significantly with the number of respiratory admissions (Table 4).

For the period 14 January-14 July, the prevalence of AR and asthma denoted notably stronger associations with the chemical and pollen variables for adults than for the elderly. For both age groups, AR shows substantially stronger associations with both types of explanatory variables than does asthma. For adults of both sexes with AR, the CO level was the most important factor associated with hospital admissions, whereas with asthma it was NO concentration. In the case of the elderly, male and female patients with AR were influenced mostly by $\mathrm{SO}_{2}$. Asthma was strongly affected by the total pollen excluding Ambrosia in males while in females it was influenced mostly by $\mathrm{CO}$. With all patients during this period, the chemical variables had a substantially higher total weight for both age categories compared to that for the total pollen level excluding Ambrosia pollen. The weight of the pollen variable was ranked five for all adults and two for all the elderly. Note, that this influencing variable is relevant for both age categories. For all adults, the total weights of the explanatory variables were far higher than those for all the elderly. In the latter category, there were fewer significant associations among the explanatory variables and the number of respiratory diseases; furthermore, the pollen variable has around half of the weight compared to the all adults category. The most relevant influencing variables, in decreasing order, were $\mathrm{NO}, \mathrm{SO}_{2}$ and $\mathrm{NO}_{2}$ for all adults, while $\mathrm{SO}_{2}$, total pollen excluding Ambrosia pollen and NO for all the elderly (Table 5). 


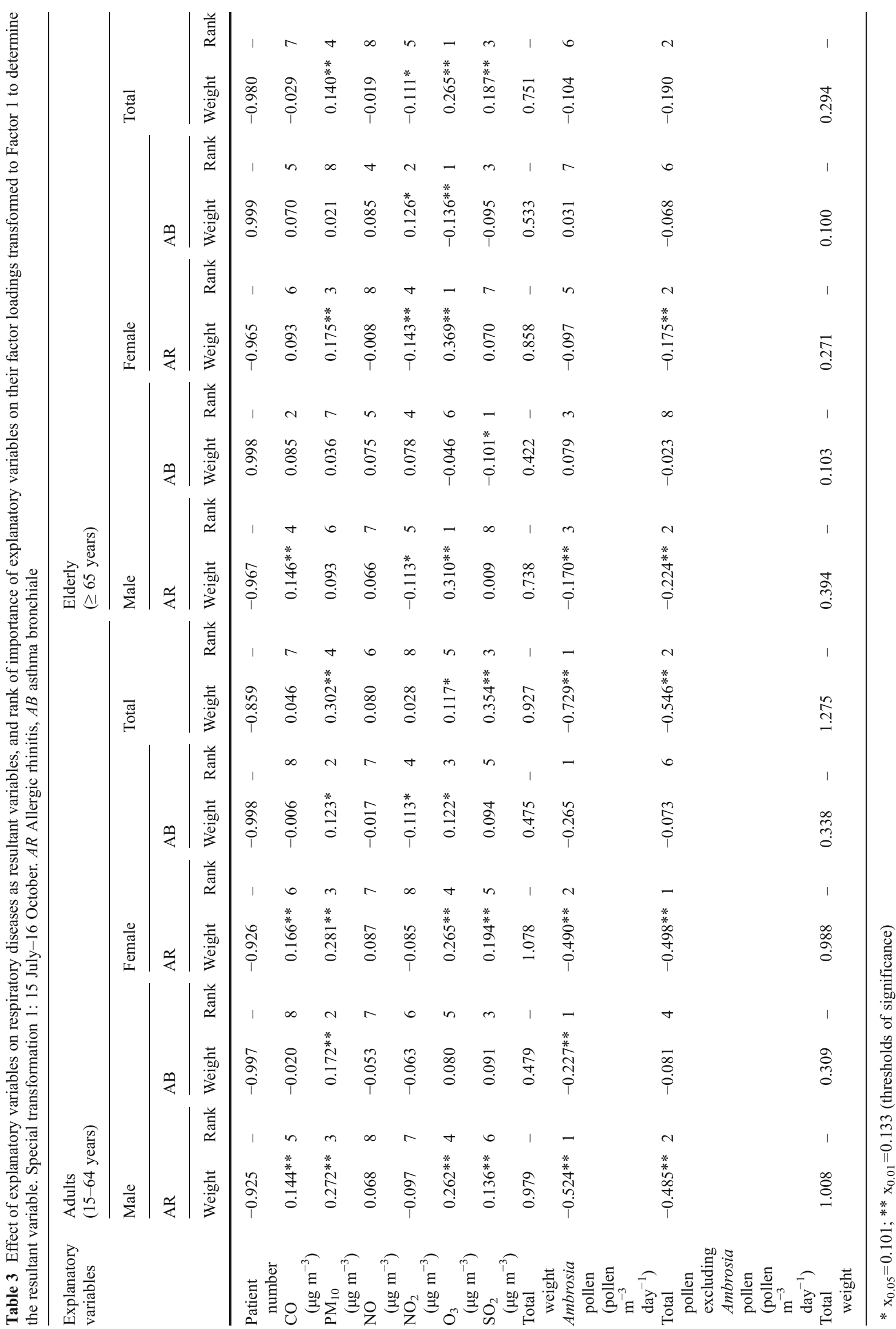


Regarding the 6-8 explanatory variables that depend on the three periods under the three quantiles, two age groups, two categories of sex and two categories of types of diseases, altogether $504 t$-tests were performed to check whether the averages of two data groups of an explanatory variable differ sigificantly. Elements of these groups were defined according to whether the actual daily patient numbers are below or above their quantile value. The results showed that $21.1 \%, 12.1 \%$ and $6.2 \%$ of average pairs differed significantly at $10 \%, 5 \%$ and $1 \%$ levels, respectively, i.e. $21.1 \%$ of all avearge pairs differed significantly at least at the $10 \%$ level. The fewest $(1.8 \%)$ statistically significant different averages (at $5 \%$ level) were in the pollen season of the total pollen excluding Ambrosia, and the other two periods gave almost the same percentage values.

Conditional probabilities and events of exceeding quantiles

The time window $b$ and the bandwidth $h$ vary from 7 to 39 days and from 1.1 to 5.1, respectively, depending on the quantiles and periods within the year. The pollination season of Ambrosia had the smallest $b$ and $h$, while the season of the remaining pollen had the largest.

Table 6 summarises the multiple correlations between the explanatory variables and the indicator variables defined by events of exceeding/not exceeding the $P$-quantile values $q_{\mathrm{p}}$. The strongest relationships between extreme patient numbers and pollutants were observed during the pollination season of Ambrosia, while the pollen-free period exhibited the lowest correlations. Another important finding is that the elderly group is characterised by weaker relationships between extreme patient numbers and pollutants.

Estimates of the quantile exceedance probabilities conditioned on the explanatory variables made it possible to create a decision of whether the patient number exceeds a quantile under an individual formation of the explanatory variables. Namely, when the estimated probability is higher (lower) than $1-p$, the answer is yes (no) for the exceedance of the $p$-quantile $q_{\mathrm{p}}$. Such a decision is called correct when the decision on the event of exceeding - not exceeding the quantile value is identical to the observed exceeding - not exceeding event. Table 7 shows the ratios of the number of correct decisions to the number of decisions of these events for $p=0.9,0.8$ and 0.7 . The lowest ratios were observed for the pollen-free season, while those for the two pollination seasons were quite similar. Again, the weakest results appeared for the elderly group, while the best ratios of the correct decisions were seen for adults (partly, with the exception of the pollen-free season). Note that percentage values of correct decisions are significantly higher for exceedance events than for events of no exceedance. The exceedance events are thus overrated, which is, however, a smaller problem than the reverse case of overrating the events of no exceedance. 


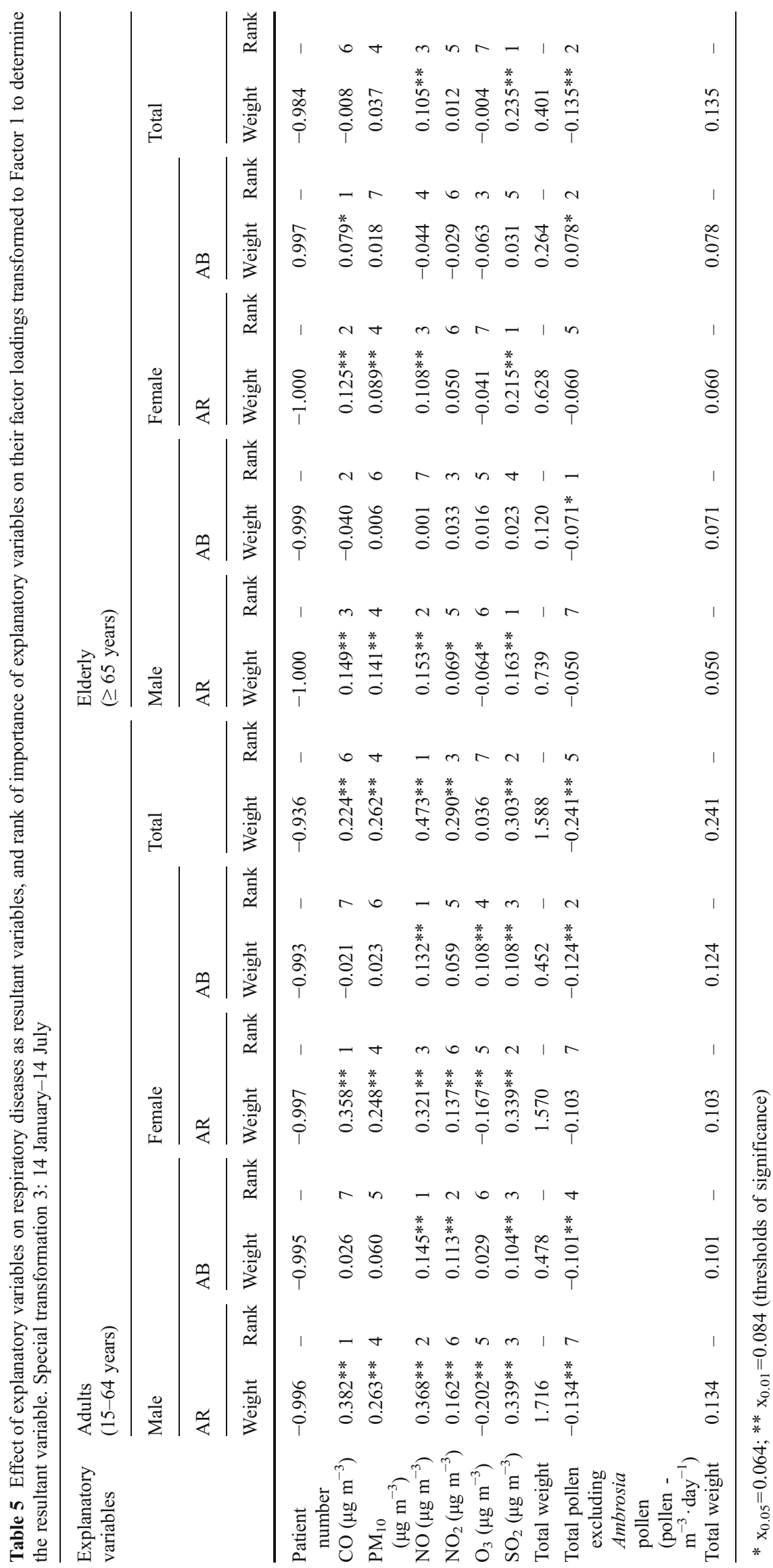


Table 6 Multiple correlation between the explanatory variables and the indicator variable defined by the events of exceeding/not exceeding the $P$ quantile value $q_{\mathrm{p}}$ for the three periods examined

\begin{tabular}{|c|c|c|c|c|c|c|c|c|}
\hline \multirow[t]{3}{*}{$P$} & \multicolumn{4}{|l|}{ Adults } & \multicolumn{4}{|l|}{ The elderly } \\
\hline & \multicolumn{2}{|l|}{ Male } & \multicolumn{2}{|l|}{ Female } & \multicolumn{2}{|l|}{ Male } & \multicolumn{2}{|l|}{ Female } \\
\hline & $\operatorname{AR}\left(q_{\mathrm{p}}\right)$ & $\mathrm{AB}\left(q_{\mathrm{p}}\right)$ & $\operatorname{AR}\left(q_{\mathrm{p}}\right)$ & $\mathrm{AB}\left(q_{\mathrm{p}}\right)$ & $\operatorname{AR}\left(q_{\mathrm{p}}\right)$ & $\mathrm{AB}\left(q_{\mathrm{p}}\right)$ & $\operatorname{AR}\left(q_{\mathrm{p}}\right)$ & $\mathrm{AB}\left(q_{\mathrm{p}}\right)$ \\
\hline \multicolumn{9}{|c|}{15 July-16 October $\left(* \mathrm{x}_{0.05}=0.100 ; * * \mathrm{x}_{0.01}=0.134\right)$} \\
\hline 0.9 & $0.52 * *(35)$ & $0.17 * *(25)$ & $0.40 * *(46)$ & $0.17 * *(35)$ & $0.19 * *(4)$ & $0.08(6)$ & $0.14^{* *}(5)$ & $0.46^{* *}(8)$ \\
\hline 0.8 & $0.53 * *(27)$ & $0.30 * *(22)$ & $0.45 * *(39)$ & $0.31 * *(30)$ & $0.14 * *(3)$ & $0.22 * *(5)$ & $0.22 * *(4)$ & $0.08(7)$ \\
\hline 0.7 & $0.52 * *(21)$ & $0.32 * *(20)$ & $0.51 * *(33)$ & $0.33 * *(27)$ & $0.27 * *(2)$ & $0.16^{* *}(4)$ & $0.28 * *(3)$ & $0.14 * *(6)$ \\
\hline \multicolumn{9}{|c|}{17 October-13 January $\left(* \mathrm{x}_{0.05}=0.096 ; * * \mathrm{x}_{0.01}=0.127\right)$} \\
\hline 0.9 & $0.19^{* *}(18)$ & $0.02(22)$ & $0.22 * *(27)$ & $0.18 * *(32)$ & $0.03(4)$ & $0.02(7)$ & $0.17 * *(5)$ & $0.05(9)$ \\
\hline 0.8 & $0.26^{* *}(14)$ & $0.11 *(19)$ & $0.34 * *(23)$ & $0.29 * *(28)$ & $0.13 *(3)$ & $0.09(5)$ & $0.25 * *(4)$ & $0.15^{* *}(7)$ \\
\hline 0.7 & $0.27 * *(12)$ & $0.11 *(17)$ & $0.34 * *(20)$ & $0.25 * *(24)$ & $0.15^{* *}(2)$ & $0.08(4)$ & $0.28 * *(3)$ & $0.19 * *(6)$ \\
\hline \multicolumn{9}{|c|}{14 January-14 July $\left(* \mathrm{x}_{0.05}=0.065 ; * * \mathrm{x}_{0.01}=0.087\right)$} \\
\hline 0.9 & $0.35^{* *}(24)$ & $0.14 * *(22)$ & $0.36 * *(35)$ & $0.08 *(31)$ & $0.07 *(4)$ & $0.02(6)$ & $0.16^{* *}(5)$ & $0.06(9)$ \\
\hline 0.8 & $0.42 * *(20)$ & $0.16^{* *}(20)$ & $0.45 * *(30)$ & $0.10 * *(27)$ & $0.06(3)$ & $0.05(5)$ & $0.18^{* *}(4)$ & $0.07 *(8)$ \\
\hline 0.7 & $0.47 * *(18)$ & $0.17 * *(18)$ & $0.49 * *(26)$ & $0.12 * *(25)$ & $0.06(2)$ & $0.06(4)$ & $0.18 * *(3)$ & $0.08 *(7)$ \\
\hline
\end{tabular}

$* \mathrm{x}_{0.05} ; * * \mathrm{x}_{0.01}$ (thresholds of significance)

\section{Discussion}

Analysis of hospital admissions due to chronic respiratory diseases associated with air pollutant concentrations is a very important issue in public health. The present study analysed one of the largest databases in the field. Our study can be considered specific in the sense that it simultaneously includes two age categories, gender, as well as AR and asthma as resultant variables, along with two categories of influencing variables with six chemical and two biological (pollen) parameters; all these associations were examined for three seasons. Besides the research team of Makra et al. (2012), we know of no study that describes such a comprehensive analysis in the field or applies these statistical

Table 7 Ratio (\%) of the number of correct decisions for events 0 and 1 to the number of observed events 0 and 1 for the three periods examined. Events 1 and 0 refer to the case when the number of patients exceeds and does not exceed the $p$-quantile value of the patients' number, respectively

\begin{tabular}{|c|c|c|c|c|c|c|c|c|c|c|c|c|c|c|c|c|}
\hline \multirow[t]{4}{*}{$p$} & \multicolumn{8}{|c|}{ Adults } & \multicolumn{8}{|c|}{ The elderly } \\
\hline & \multicolumn{4}{|l|}{ Male } & \multicolumn{4}{|c|}{ Female } & \multicolumn{4}{|l|}{ Male } & \multicolumn{4}{|c|}{ Female } \\
\hline & \multicolumn{2}{|l|}{$\mathrm{AR}$} & \multicolumn{2}{|l|}{$\mathrm{AB}$} & \multicolumn{2}{|l|}{$\mathrm{AR}$} & \multicolumn{2}{|l|}{$\mathrm{AB}$} & \multicolumn{2}{|l|}{$\mathrm{AR}$} & \multicolumn{2}{|l|}{$\mathrm{AB}$} & \multicolumn{2}{|l|}{$\mathrm{AR}$} & \multicolumn{2}{|l|}{$\mathrm{AB}$} \\
\hline & 0 & 1 & 0 & 1 & 0 & 1 & 0 & 1 & 0 & 1 & 0 & 1 & 0 & 1 & 0 & 1 \\
\hline \multicolumn{17}{|c|}{15 July-16 October } \\
\hline 0.9 & 81.5 & $80.0^{\mathrm{a}}$ & 64.6 & $73.5^{\mathrm{a}}$ & 67.7 & $85.7^{\mathrm{a}}$ & 65.9 & $66.7^{\mathrm{a}}$ & 78.2 & $54.5^{\mathrm{a}}$ & 85.6 & $19.0^{\mathrm{a}}$ & 59.5 & $54.3^{\mathrm{a}}$ & 82.2 & $29.6^{\mathrm{a}}$ \\
\hline 0.8 & 71.0 & $82.6^{\mathrm{a}}$ & 65.8 & $68.2^{\mathrm{a}}$ & 62.8 & $88.9^{\mathrm{a}}$ & 63.0 & $71.2^{\mathrm{a}}$ & $97.0^{\mathrm{a}}$ & 7.0 & 82.6 & $50.0^{\mathrm{a}}$ & 73.8 & $52.4^{\mathrm{a}}$ & $98.5^{\mathrm{a}}$ & 4.1 \\
\hline 0.7 & 68.8 & $78.2^{\mathrm{a}}$ & 71.1 & $57.6^{\mathrm{a}}$ & 68.4 & $79.4^{\mathrm{a}}$ & 63.5 & $65.5^{\mathrm{a}}$ & $84.2^{\mathrm{a}}$ & $38.0^{\mathrm{a}}$ & $81.7^{\mathrm{a}}$ & 27.2 & $74.8^{\mathrm{a}}$ & $54.1^{\mathrm{a}}$ & $98.3^{\mathrm{a}}$ & 1.3 \\
\hline \multicolumn{17}{|c|}{17 October-13 January } \\
\hline 0.9 & 68.1 & $54.1^{\mathrm{a}}$ & 80.0 & $30.0^{\mathrm{a}}$ & 65.3 & $62.5^{\mathrm{a}}$ & 74.9 & $48.5^{\mathrm{a}}$ & 83.8 & $12.0^{\mathrm{a}}$ & 89.6 & $25.0^{\mathrm{a}}$ & 75.4 & $51.7^{\mathrm{a}}$ & 81.0 & $30.0^{\mathrm{a}}$ \\
\hline 0.8 & 60.9 & $64.9^{\mathrm{a}}$ & 57.0 & $60.3^{\mathrm{a}}$ & 62.8 & $69.6^{\mathrm{a}}$ & 71.0 & $60.0^{\mathrm{a}}$ & 76.2 & $38.8^{\mathrm{a}}$ & 62.5 & $45.2^{\mathrm{a}}$ & $86.1^{\mathrm{a}}$ & $32.7^{\mathrm{a}}$ & 48.7 & $65.8^{\mathrm{a}}$ \\
\hline 0.7 & 64.4 & $57.0^{\mathrm{a}}$ & 59.6 & $47.8^{\mathrm{a}}$ & 58.2 & $72.7^{\mathrm{a}}$ & 56.2 & $60.2^{\mathrm{a}}$ & $71.3^{\mathrm{a}}$ & $39.1^{\mathrm{a}}$ & 49.7 & $61.5^{\mathrm{a}}$ & 68.8 & $56.0^{\mathrm{a}}$ & 48.7 & $69.7^{\mathrm{a}}$ \\
\hline \multicolumn{17}{|c|}{14 January-14 July } \\
\hline 0.9 & 65.5 & $87.8^{\mathrm{a}}$ & 63.1 & $56.3^{\mathrm{a}}$ & 62.9 & $89.2^{\mathrm{a}}$ & 63.1 & $47.8^{\mathrm{a}}$ & $98.4^{\mathrm{a}}$ & 0.0 & $95.8^{\mathrm{a}}$ & 6.6 & 71.1 & $48.5^{\mathrm{a}}$ & $92.1^{\mathrm{a}}$ & $13.5^{\mathrm{a}}$ \\
\hline 0.8 & 64.7 & $81.9^{\mathrm{a}}$ & 75.5 & $40.9^{\mathrm{a}}$ & 62.6 & $86.2^{\mathrm{a}}$ & 71.7 & $37.4^{\mathrm{a}}$ & $100.0^{\mathrm{a}}$ & 0.0 & $100.0^{\mathrm{a}}$ & 0.0 & $94.4^{\mathrm{a}}$ & 13.0 & 60.8 & $40.8^{\mathrm{a}}$ \\
\hline 0.7 & 68.1 & $81.4^{\mathrm{a}}$ & $83.8^{\mathrm{a}}$ & $25.5^{\mathrm{a}}$ & $70.2^{\mathrm{a}}$ & $76.8^{\mathrm{a}}$ & $91.5^{\mathrm{a}}$ & 17.0 & $100.0^{\mathrm{a}}$ & 0.0 & $94.6^{\mathrm{a}}$ & 5.4 & $88.7^{\mathrm{a}}$ & $36.4^{\mathrm{a}}$ & 60.1 & $42.3^{\mathrm{a}}$ \\
\hline
\end{tabular}

${ }^{\text {a }}$ Values higher than the reference percentage values defined in the article 
procedures. Nevertheless, we know of one study (Chen et al. 2006) that calculated seasonal variations of respiratory admissions in association with levels of $\mathrm{PM}_{10}, \mathrm{SO}_{2}, \mathrm{CO}$ and $\mathrm{NO}_{2}$, and one other study (Kassomenos et al. 2008) that made an attempt to quantify the impact of different chemical pollutants, including meteorological elements, on the incidence of AR and asthma. However, pollen data have not been studied from this point of view.

Factor analysis with a special transformation was applied in order to examine the role of pollen variables and chemical air pollutants in respiratory hospital admissions and to determine the rank of importance of these variables in influencing the prevalence of chronic respiratory diseases. After calculating high quantiles corresponding to probability distributions of respiratory hospital admissions, the averages of two data sets of each air pollutant variable were compared and evaluated. Elements of these data sets were chosen according to whether actual daily patient numbers were below or above their quantile value.

For all three seasons examined, the prevalence of admission due to AR and asthma exhibited notably stronger associations with the chemical and pollen variables in adults than in elderly people (Table 3). Asthma in the elderly is frequently underdiagnosed and undertreated (Bauer et al. 1997). Assessment of the disesase is complicated by different factors, namely a poor perception of the symptoms, acceptance of dyspnoe as being "normal" in old age, and reduced expectations of mobility and activity (Global Strategy for Asthma Management and Prevention 2011).

AR in both adult and elderly patients exhibits substantially stronger associations with both types of explanatory variables, than that for asthma (Table 3). Several reasons might explain this. The majority of asthmatic patients can control or partly control the disease with regular long-term treatment and go to their doctor only in case of emergency or the lack of effectiveness of their usual therapy. However, for some subjects, late admissions of neglected or untreated AR can induce inflammation in the lower respiratory tract and hence lead to asthma (Miguel et al. 2006). This leads to an apparently higher prevalence of AR and asthma. Morever, asthma can also develop independently. Whole pollen grains can provoke AR, while smaller pollen fragments capable of becoming deposited in the lower respiratory tract have been proposed as the trigger for asthma (Miguel et al. 2006). Based on the total weights of the disease groups, the effect of the chemical and pollen variables was highest for the occurrence of respiratory admissions for the period 15 July-16 October (Table 3), due mainly to the extra impact of Ambrosia pollen on the chemical variables and the remaining pollen. Key pollutants differ in the two age categories depending on the season, sex and disease types.
In most cases, we found substantial negative associations between $\mathrm{CO}$ levels and the different categories of patients. However, positive connections, and in some cases no clear associations, were also found (Tables 3-5). Freitas et al. (2010) found no statistically significant relationship between respiratory hospital admissions and $\mathrm{CO}$, while Fusco et al. (2001) and Kassomenos et al. (2008) confirmed the positive role of $\mathrm{CO}$ on respiratory health effects. The impact of a long-lasting but low level exposure to $\mathrm{CO}$ on the respiratory system is therefore still unclear.

For different seasons and categories, diverse significant associations were found between patient numbers and $\mathrm{PM}_{10}$ levels in some cases, while in others no important connection was found (Tables 3-5). Katsouyanni et al. (1996) and Fusco et al. (2001) suggested that gaseous air pollutants, especially $\mathrm{CO}$ and $\mathrm{NO}_{2}$, are more important predictors of acute hospitalization for respiratory conditions than particulate matter. In contrast, Kassomenos et al. (2008) found that elevated $\mathrm{PM}_{10}$ levels play a dominant role among the main air pollutants. Fusco et al. (2001) and Alves et al. (2010) found that the association between particulate matter and health conditions was not significant, while others (Hajat et al. 2002; Ko et al. 2007; Freitas et al. 2010; Zhang et al. 2011) found that the number of admissions for respiratory causes rose significantly with increased exposure to particulate matter. It should be added that the health impact of particulates is complex as their biological effect can be influenced by particle size and composition (Alves et al. 2010).

Significant associations of $\mathrm{NO}$ and $\mathrm{NO}_{2}$ are positive with $\mathrm{AR}$ and asthma in both the periods 15 July-16 October and 17 October-13 January while, conversely, they are inversely associated with the respiratory diseases in the period 14 January-14 July (Tables 3-5). Although $\mathrm{NO}$ and $\mathrm{NO}_{2}$ are thought to increase the predisposition to respiratory diseases, there is still a disparity between the results of different studies on the association between $\mathrm{NO}_{\mathrm{x}}$ and respiratory causes. For example, high levels of $\mathrm{NO}_{2}$ sometimes indicate no significant association with respiratory admissions (Alves et al. 2010) and sometimes increase susceptibility to respiratory diseases (Freitas et al. 2010). Other examples of the significant positive impact of $\mathrm{NO}_{2}$ levels on respiratory causes were reported by Fusco et al. (2001), Kassomenos et al. (2008) and Zhang et al. (2011).

Several studies have suggested that high concentrations of $\mathrm{O}_{3}$ are harmful to human health and reveal a positive association between $\mathrm{O}_{3}$ and respiratory hospital admissions (e.g. Kassomenos et al. 2008). Furthermore, the lowest ozone concentrations in the winter months were found to involve an apparent decrease in consultations for AR in London (Hajat et al. 2002). In contrast, we observed both statistically significant negative and positive associations between ozone concentrations 
and admissions due to respiratory symptoms (Tables 3-5). Several studies suggest that high concentrations of $\mathrm{O}_{3}$ are harmful to human health and reveal a positive association between $\mathrm{O}_{3}$ and respiratory hospital admissions (e.g. Kassomenos et al. 2008). Furthermore, the lowest ozone concentrations in the winter months were found to involve an apparent decrease in consultations for $\mathrm{AR}$ in London (Hajat et al. 2002). In contrast, we observed both statistically significant negative and positive associations between ozone concentrations and admissions due to respiratory symptoms (Tables 3-5).

The interpretation of these findings is not straightforward. However, it has been found that $\mathrm{O}_{3}$ and $\mathrm{NO}_{2}$, with or without $\mathrm{SO}_{2}$, can enhance the airway allergic response in susceptible individuals such as those with asthma and rhinitis. Investigating cellular and subcellular mechanisms suggest that pollutants are likely to influence the actions and interactions of a variety of cells, and lead to the synthesis of pro-inflammatory mediators that modulate the activity and functions of inflammatory cells (Davies et al. 1998). As there is no evidence that low levels of ozone are harmful, this association seems paradoxical. The phenomenon known as paradoxical ozone association (POA; Joseph 2007) could be due to methyl nitrite from some combustion of methyl ethers or esters in engine fuels. Methyl nitrite is known to be highly toxic, and closely related alkyl nitrites are known to induce respiratory sensitivity in humans (Joseph and Weiner 2002). Since sunlight is essential for ozone formation by photochemical oxidation, a probable explanation for POA is the existence of this nitrite pollutant, which is destroyed rapidly by solar radiation. Hence, methyl nitrite is correlated negatively with $\mathrm{O}_{3}$. Since sunlight has the opposite effect on methyl nitrite, one would expect the most acute methyl nitrite effect in winter (Joseph 2007). A negative association between $\mathrm{O}_{3}$ levels and respiratory diseases in the summer period (15 July-16 October, Table 3) can be explained by the fact that our monitoring station is situated at a junction with a high traffic volume.

We found a significant negative association between $\mathrm{SO}_{2}$ levels and admissions due to AR and asthma for the different categories (Tables 3-5). At the same time, previous findings concerning the role of $\mathrm{SO}_{2}$ seem inconsistent. This pollutant was not significantly associated with respiratory diseases in studies by Katsouyanni et al. (1996) or Ko et al. (2007), but other studies reported positive relationships (Hajat et al. 2002; Kassomenos et al. 2008; Alves et al. 2010; Zhang et al. 2011).

Ambrosia pollen levels have a significant positive association with each disease group of adults, the total number of adults, as well as AR in elderly males and the total number of elderly patients (Table 3 ). Similar results can be found e.g. in Carracedo-Martínez et al. (2008); Erkara et al. (2009) and Zhang et al. (2011).

The results obtained for the elderly, especially concerning pollen variables (Table 3) differ substantially from those determined for adults for all three seasons examined. Some habits of elderly people, such as social factors, leads them to tend to underestimate chronic diseases and consider them as a natural attendant of ageing. Hence, the elderly often do not turn to a physician and seek medical treatment in time (Johnson 2005).

Multiple correlations between the explanatory variables and the indicator variables defined by events of exceeding/not exceeding the $p$-quantile values $q_{\mathrm{p}}$ (Table 6) show that strongest relationships between extreme patient numbers and pollutants can be observed during the pollination season of Ambrosia. In contrast, the pollination season of all taxa excluding Ambrosia exhibits the lowest correlations. Another important finding is that the elderly group is characterised by substantially weaker relationships between extreme patient numbers and pollutants. These results are in good agreement with those of the factor analysis (see total weights in Table 6).

Similar conclusions can be drawn from Table 7. The ratio of the number of correct decisions to the number of decisions of events exceeding/not exceeding a quantile under individual formations of the explaining variables is lowest for the pollination season of all taxa excluding Ambrosia, while it is highest in the pollination season of Ambrosia. Again, much weaker results appear for the elderly group, while the best ratios of correct decisions can be seen for adults. Extreme patient numbers with AR can be estimated substantially better than those with asthma. Unfortunately, estimates of extreme patient numbers are of no use during the pollination season of all taxa excluding Ambrosia for elderly males. The percentage values in Table 7 can be compared with some reference percentage values as follows. If we omit the information of explanatory variables on daily patient numbers and decide the event of exceeding (not exceeding) the $p$-quantile $q_{\mathrm{p}}$ for each day, the percentage of correct decisions will be $100 \times(1-p) \%(100 \times p \%)$. These values are taken as reference percentage values because the decision procedure involving explanatory variables should provide higher percentage values of correct decisions if air pollutants have an influence on extreme patient numbers.

\section{Conclusions}

In the three seasons examined, the frequency of hospital admissions due to AR and asthma represents significantly stronger associations with the chemical and pollen variables for adults than those for the elderly. Furthermore, in the case 
of adult and elderly patients, AR has substantially stronger associations with both types of explanatory variables than does asthma. Based on the total weights of the disease groups, the effect of the chemical and pollen variables is highest for the occurrence of respiratory hospital admissions in the period 15 July-16 October, due mainly to the extra impact of Ambrosia pollen on the chemical variables and the remaining pollen.

For adult patients, the total weight of chemical variables in the occurrence of respiratory admissions is higher in pollen-related seasons compared to the pollen-free season. This may be explained by the fact that air pollutants can affect allergens, e.g. pollen morphology, and thus change their allergenic potency.

Key pollutants differ for adults and the elderly depending on season, gender and disease type. As regards the concentrations of air pollutants, estimation of the extreme daily number of patients is best in the case of adults with AR and worst in the case of the elderly during pollen-related seasons. The pollen-free season does not exhibit substantial differences among ages, genders and types of respiratory disease. These findings suggest that a combination of chemical and pollen variables affects subjects with different ages and diseases types in a variety of ways.

Acknowledgements The authors would like to thank Gábor Motika (Environmental Conservancy Inspectorate, Szeged, Hungary) for providing chemical air pollutant data of Szeged, Miklós Juhász (University of Szeged) for providing pollen data of Szeged and Zoltán Sümeghy (University of Szeged) for the digital mapping in Fig. 1. The authors gratefully acknowledge the anonymous reviewers for their constructive comments, advice and suggestions. The European Union and the European Social Fund provided financial support for the project under the grant agreement no. TAMOP 4.2.1/B-09/1/KMR2010-0003, TAMOP-4.2.1/B-09/1/KONV-2010-0005 and TAMOP4.2.2/B-10/1-2010-0012.

\section{References}

Ågren C (2010) Particles killing half a million. Acid News. AirClim. Air Pollution \& Climate Secretariat, Sweden 2:1-5 http:// www.airclim.org/acidnews/2010/AN2-10.php\#1

Albertini R, Ugolotti M, Peveri S, Valenti MT, Usberti I, Ridolo E, Dall'Aglio P (2012) Evolution of ragweed pollen concentrations, sensitization and related allergic clinical symptoms in Parma (northern Italy). Aerobiologia 28:347-354. doi:10.1007/s10453011-9239-6

Alves CA, Scotto MG, Freitas MC (2010) Air pollution and emergency admissions for cardiorespiratory diseases in Lisbon (Portugal). Quim Nova 33:337-344. doi:10.1590/S010040422010000200020

Andersen ZJ, Wahlin P, Raaschou-Nielsen O, Scheike T, Loft S (2007) Ambient particle source apportionment and daily hospital admissions among children and the elderly in Copenhagen. J Expo Sci Environ Epidemiol 17:625-636. doi:10.1038/sj.jes.7500546
Barrett K, de Leeuw F, Fiala J, Larssen S, Sundvor I, Fjellsbø L, Dusinska M, Ostatnická J, Horálek J, Černikovský L, Barmpas F, Moussipoulos N, Vlahocostas C (2008) Health impacts and air pollution - an exploration of factors influencing estimates of air pollution impact upon the health of European citizens. ETC/ACC Tech Pap 13

Bauer BA, Reed CE, Yunginger JW, Wollan PC, Silverstein MD (1997) Incidence and outcomes of asthma in the elderly-a population-based study in Rochester, Minnesota. Chest 111(2):303-310. doi:10.1378/chest.111.2.303

Carracedo-Martínez E, Sánchez C, Taracido M, Saez M, Jato V, Figueiras A (2008) Effect of short-term exposure to air pollution and pollen on medical emergency calls: a case-crossover study in Spain. Allergy 63:347-353. doi:10.1111/j.1398-9995.2007.01574.x

Cecchi L, D’Amato G, Ayres JG, Galán C, Forastiere F, Forsberg B, Gerritsen J, Nunes C, Behrendt H, Akdis C, Dahl R, AnnesiMaesano I (2010) Projections of the effects of climate change on allergic asthma: the contribution of aerobiology. Allergy 65:1073-1081. doi:10.1111/j.1398-9995.2010.02423.x

Chen CH, Xirasagar S, Lin HC (2006) Seasonality in adult asthma admissions, air pollutant levels, and climate: a population-based study. J Asthma 43:287-292. doi:10.1080/02770900600622935

Chiu HF, Cheng MH, Yang CY (2009) Air pollution and hospital admissions for pneumonia in a subtropical city: Taipei, Taiwan. Inhal Toxicol 21:32-37. doi:10.1080/08958370802441198

Chiusolo M, Cadum E, Stafoggia M, Galassi C, Berti G, Faustini A, Bisanti L, Vigotti MA, Dessi MP, Cernigliaro A, Mallone S, Pacelli B, Minerba S, Simonato L, Forastiere F (2011) Short-term effects of nitrogen dioxide on mortality and susceptibility factors in 10 Italian cities: the EpiAir study. Environ Health Perspect 119:1233-1238. doi:10.1289/ehp.1002904

Chung KAF, Zhang JF, Zhong NS (2011) Outdoor air pollution and respiratory health in Asia. Respirology 16:1023-1026. doi:10.1111/j.1440-1843.2011.02034.x

Cohen AJ, Anderson HR, Ostro B, Pandey KD, Krzyzanowski M, Künzli N, Gutschmidt K, Pope A, Romieu I, Samet JM, Smith $\mathrm{K}$ (2005) The global burden of disease due to outdoor air pollution. J Toxicol Environ Health A 68:1301-1307. doi:10.1080/ 15287390590936166

Darrow LA, Klein M, Sarnat JA, Mulholland JA, Strickland MJ, Sarnat SE, Russell AG, Tolbert PE (2011) The use of alternative pollutant metrics in time-series studies of ambient air pollution and respiratory emergency department visits. J Expo Sci Environ Epidemiol 21:10-19. doi:10.1038/jes.2009.49

Davies RJ, Rusznak C, Devalia JL (1998) Why is allergy increasing? Environmental factors. Clin Exp Allergy 28:8-14

Díaz J, Linares C, Tobías A (2007) Short-term effects of pollen species on hospital admissions in the city of Madrid in terms of specific causes and age. Aerobiologia 23:231-238. doi:10.1007/s10453007-9067-x

Dullaers M, De Bruyne R, Ramadani F, Gould HJ, Gevaert P, Lambrecht BN (2012) The who, where, and when of IgE in allergic airway disease. J Allergy Clin Immunol 129:635-645. doi:10.1016/j.jaci.2011.10.029

Erkara I, Cingi C, Ayranci U, Gurbuz K, Pehlivan S, Tokur S (2009) Skin prick test reactivity in allergic rhinitis patients to airborne pollens. Environ Monit Assess 151:401-412. doi:10.1007/ s10661-008-0284-8

Fan J, Yao Q (2005) Nonlinear time series: nonparametric and parametric methods. Springer, New York

Fischer G, Roppert J (1965) Ein Verfahren der Transformationsanalyse faktorenanalytischer Ergebnisse. In: Lineare Strukturen in Mathematik und Statistik unter besonderer Berücksichtigung der Faktoren- und Transformationsanalyse. Arbeiten aus dem Institut für höhere Studien und wissenschaftliche Forschung. Physica, Vienna 
Freitas MC, Pacheco AMG, Verburg TG, Wolterbeek HAT (2010) Effect of particulate matter, atmospheric gases, temperature, and humidity on respiratory and circulatory diseases' trends in Lisbon, Portugal. Environ Monit Assess 162:113-121. doi:10.1007/ s10661-009-0780-5

Fusco D, Forastiere F, Michelozzi P, Spadea T, Ostro B, Arca M, Perucci CA (2001) Air pollution and hospital admissions for respiratory conditions in Rome, Italy. Eur Respir J 17:11431150. doi:10.1183/09031936.01.00005501

Galán C, Cariňanos P, García-Mozo H, Alcázar P, Domínguez-Vilches E (2001) Model for forecasting Olea europaea $L$. airborne pollen in South-West Andalusia, Spain. Int J Biometeorol 45:59-63. doi:10.1007/s004840100089

Giovannini M, Sala M, Riva E, Radaelli G (2010) Hospital admissions for respiratory conditions in children and outdoor air pollution in Southwest Milan, Italy. Acta Paediatr 99:1180-1185. doi:10.1111/ j.1651-2227.2010.01786.x

Global Strategy for Asthma Management and Prevention (2010) $103 p$ http://www.ginasthma.org/pdf/GINA_Report 2010.pdf Accessed 6 August 2012

Global Strategy for Asthma Management and Prevention (2011) http:// www.ginasthma.org/pdf/GINA_Report_2011.pdf

Gowers AM, Cullinan P, Ayres JG, Anderson HR, Strachan DP, Holgate ST, Mills IC, Maynard RL (2012) Does outdoor air pollution induce new cases of asthma? Biological plausibility and evidence; a review. Respirology 17:887-898. doi:10.1111/ j.1440-1843.2012.02195.x

Hajat S, Anderson HR, Atkinson RW, Haines A (2002) Effects of air pollution on general practitioner consultations for upper respiratory diseases in London. Occup Environ Med 59:294-299. doi:10.1136/oem.59.5.294

Hanigan IC, Johnston FH (2007) Respiratory hospital admissions were associated with ambient airborne pollen in Darwin, Australia, 2004-2005. Clin Exp Allergy 37:1556-1565. doi:10.1111/ j.1365-2222.2007.02800.x

Hirst JM (1952) An automatic volumetric spore trap. Ann Appl Biol 39:257-265

Jahn W, Vahle H (1968) Die Faktoranalyse und ihre Anwendung. Wirtschaft, Berlin

Járai-Komlódi M (1998) Ragweed in Hungary. In: (Spieksma FThM, ed.) Ragweed in Europe. Satellite Symposium Proceedings of 6th International Congress on Aerobiology. Perugia, Italy. AlkAbelló, Horsholm, pp 33-38

Jeffery PK, Haahtela T (2006) Allergic rhinitis and asthma: inflammation in a one airway condition. BMC Pulm Med 6(Suppl 1):S5

Johnson ML (ed) (2005) The Cambridge handbook of age and ageing. Cambridge University Press, Cambridge

Jolliffe IT (1993) Principal component analysis: a beginner's guideII. Pitfalls, myths and extensions. Weather 48:246-253

Joseph PM (2007) Paradoxical ozone associations could be due to methyl nitrite from combustion of methyl ethers or esters in engine fuels. Environ Int 33:1090-1106. doi:10.1016/j.envint.2007.07.001

Joseph PM, Weiner MG (2002) Visits to physicians after the oxygenation of gasoline in Philadelphia. Arch Environ Health 57:137154

Käpylä M, Penttinen A (1981) An evaluation of the microscopial counting methods of the tape in Hirst-Burkard pollen and spore trap. Grana 20:131-141. doi:10.1080/00173138109427653

Kassomenos P, Papaloukas C, Petrakis M, Karakitsios S (2008) Assessment and prediction of short term hospital admissions: the case of Athens, Greece. Atmos Environ 42:7078-7086. doi:10.1016/j.atmosenv.2008.06.011

Katsouyanni K, Zmirou D, Spix C (1996) Short-term effects of urban air pollution on health: a European approach using epidemiologic time series data. The APHEA protocol. J Epidemiol Commun $\mathrm{H}$ 5:S12-S18. doi:10.1136/jech.50.Suppl_1.S12
Kelly FJ, Fussell JC (2011) Air pollution and airway disease. Clin Exp Allergy 41:1059-1071. doi:10.1111/j.1365-2222.2011.03776.x

Kim BJ, Kwon JW, Seo JH, Kim HB, Lee SY, Park KS, Yu J, Kim HC, Leem JH, Sakong J, Kim SY, Lee CG, Kang DM, Ha M, Hong YC, Kwon HJ, Hong SJ (2011) Association of ozone exposure with asthma, allergic rhinitis, and allergic sensitization. Ann Allerg Asthma Im 107:214-219. doi:10.1016/j.anai.2011.05.025

Kiss L, Béres I (2006) Anthropogenic factors behind the recent population expansion of common ragweed (Ambrosia artemisiifolia L.) in Eastern Europe: is there a correlation with political transitions? J Biogeogr 33:2156-2157. doi:10.1111/j.13652699.2006.01633.x

Knight A, Drouin MA, Yang WH, Alexander M, Delcarpio J, Arnott WS (1991) clinical-evaluation of the efficacy and safety of noberastine, a new $\mathrm{H} 1$ antagonist, in seasonal allergic rhinitis - a placebo-controlled, dose-response study. J Allergy Clin Immun 88:926-934. doi:10.1016/00916749(91)90250-R

Ko FWS, Tam W, Wong TW, Lai CKW, Wong GWK, Leung TF, Ng SSS, Hui DSC (2007) Effects of air pollution on asthma hospitalisation rates in different age groups in Hong Kong. Clin Exp Allergy 37:1312-1319. doi:10.1111/j.13652222.2007.02791.x

Koppen G, Bloemen K, Colles A, Nelen V, Desager K, Schoeters G (2011) Exposure to traffic-related air pollutants in the perinatal period of life in relation to respiratory health in infancy. Crit Rev Environ Sci Technol 41:2003-2025. doi:10.1080/10643389.2010.495643

Kupczyk M, Wenzel S (2012) US and European severe asthma cohorts: what can they teach us about severe asthma? J Intern Med 272:121-132. doi:10.1111/j.1365-2796.2012.02558.x

Liu PWG (2009) Simulation of the daily average $\mathrm{PM}_{10}$ concentrations at Ta-Liao with Box-Jenkins time series models and multivariate analysis. Atmos Environ 43:2104-2113. doi:10.1016/ j.atmosenv.2009.01.055

Magas OK, Gunter JT, Regens JL (2007) Ambient air pollution and daily pediatric hospitalizations for asthma. Environ Sci Pollut R 14:19-23. doi:10.1065/espr2006.08.333

Makra L, Juhász M, Béczi R, Borsos E (2005) The history and impacts of airborne Ambrosia (Asteraceae) pollen in Hungary. Grana 44:57-64. doi:10.1080/00173130510010558

Makra L, Matyasovszky I, Bálint B (2012) Association of allergic asthma emergency room visits with the main biological and chemical air pollutants. Sci Total Environ 432:288-296. doi:10.1016/j.scitotenv.2012.05.088

Martinez FD (2007) Genes, environments, development and asthma: a reappraisal. Eur Respir J 29:179-184. doi:10.1183/ 09031936.00087906

Miguel AG, Taylor PE, House J, Glovsky MM, Flagan RC (2006) Meteorological influences on respirable fragment release from Chinese elm pollen. Aerosol Sci Technol 40:690-696. doi: $10.1080 / 02786820600798869$

Miller RL, Ho SM (2008) Environmental epigenetics and asthma current concepts and call for studies. Am J Respir Crit Care Med 177:567-573. doi:10.1164/rccm.200710-1511PP

Namdeo A, Tiwary A, Farrow E (2011) Estimation of age-related vulnerability to air pollution: assessment of respiratory health at local scale. Environ Int 37:829-837. doi:10.1016/j.envint.2011.02.002

Nascimento LFC, Pereira LAA, Braga ALF, Modolo MCC, Carvalho JA (2006) Effects of air pollution on children's health in a city in Southeastern Brazil. Rev Saude Publ 40:77-82

Nuvolone D, della Maggiore R, Maio S, Fresco R, Baldacci S, Carrozzi L, Pistelli F, Viegi G (2011) Geographical information system and environmental epidemiology: a cross-sectional spatial analysis of the effects of traffic-related air pollution on population respiratory 
health. Environ Health 10: Article No. 12 doi:10.1186/1476069X-10-12

Orazzo F, Nespoli L, Ito K, Tassinari D, Giardina D, Funis M, Cecchi A, Trapani C, Forgeschi G, Vignini M, Nosetti L, Pigna S, Zanobetti A (2009) Air pollution, aeroallergens, and emergency room visits for acute respiratory diseases and gastroenteric disorders among young children in six Italian cities. Environ Health Perspect 117:1780-1785. doi:10.1289/ehp.0900599

Peternel R, Culig J, Hrga I, Hercog P (2006) Airborne ragweed (Ambrosia artemisiifolia L.) pollen concentrations in Croatia, 2002-2004. Aerobiologia 22:161-168. doi:10.1007/s10453-006-9028-9

Rogers CA, Wayne PM, Macklin EA, Muilenberg ML, Wagner CJ, Epstein PR, Bazzaz FA (2006) Interaction of the onset of spring and elevated atmospheric $\mathrm{CO}_{2}$ on ragweed (Ambrosia artemisiifolia L.) pollen production. Environ Health Perspect 114:865-869. doi:10.1289/ehp.8549

Sacks JD, Stanek LW, Luben TJ, Johns DO, Buckley BJ, Brown JS, Ross M (2011) Particulate matter-induced health effects: who is susceptible? Environ Health Perspect 119:446-454. doi:10.1289/ ehp. 1002255

Tramuto F, Cusimano R, Cerame G, Vultaggio M, Calamusa G, Maida CM, Vitale F (2011) Urban air pollution and emergency room admissions for respiratory symptoms: a case-crossover study in Palermo, Italy. Environ Health 10: Article No. 31 doi:10.1186/ 1476-069X-10-31

World Health Organization (1992) Acute effects on health of smog episodes. WHO Regional Publications, European Series, 43 WHO Regional Office for Europe, Geneva
World Health Organization (1999) Manual of the international statistical classification of diseases, injuries, and causes of death, 10th revision. World Health Organization, Geneva

Zhang F, Wang W, Lv J, Krafft T, Xu J (2011) Time-series studies on air pollution and daily outpatient visits for allergic rhinitis in Beijing, China. Sci Total Environ 409:2486-2492. doi:10.1016/ j.scitotenv.2011.04.007

Ziello C, Sparks TH, Estrella N, Belmonte J, Bergmann KC, Bucher E, Brighetti MA, Damialis A, Detandt M, Galan C, Gehrig R, Grewling L, Bustillo AMG, Hallsdottir M, Kockhans-Bieda MC, De Linares C, Myszkowska D, Paldy A, Sanchez A, Smith M, Thibaudon M, Travaglini A, Uruska A, Valencia-Barrera RM, Vokou D, Wachter R, de Weger LA, Menzel A (2012) Changes to airborne pollen counts across Europe. Plos One 7: Article No. e34076 doi:10.1371/ journal.pone.0034076

Zimmerman DW (1997) A note on interpretation of the paired-samples $t$ test. J Educ Behav Stat 22:349-360. doi:10.3102/ 10769986022003349

Ziska LH, Caulfield FA (2000) Rising $\mathrm{CO}_{2}$ and pollen production of common ragweed (Ambrosia artemisiifolia), a known allergyinducing species: implications for public health. Aust J Plant Physiol 27:893-898

Ziska LH, George K, Frenz DA (2007) Establishment and persistence of common ragweed (Ambrosia artemisiifolia) in disturbed soil as a function of an urban-rural macroenvironment. Glob Change Biol 13:266-274. doi:10.1111/ $1365-2486.2006 .01264 . x$ 